\title{
BMJ Open Quality Alert Cards to improve awareness of an otological emergency
}

\author{
Joshua James Brown, ${ }^{1}$ Anne May, ${ }_{1}^{1}$ Rose Crabtree, ${ }^{1}$ Beatrice Emmanouil, ${ }^{1}$ \\ Dorothy Halliday, ${ }^{1,2}$ Allyson Parry, ${ }^{1}$ Samuel Mackeith ${ }^{1,3}$
}

To cite: Brown JJ, May A, Crabtree R, et al. Alert Cards to improve awareness of an otological emergency. BMJ Open Quality 2021;10:e000906. doi:10.1136/ bmjoq-2019-000906

Received 6 January 2020 Revised 6 January 2021 Accepted 21 January 2021

Check for updates

(c) Author(s) (or their employer(s)) 2021. Re-use permitted under CC BY-NC. No commercial re-use. See rights and permissions. Published by BMJ.

${ }^{1}$ Neurofibromatosis 2 Centre, Oxford University Hospitals NHS Foundation Trust, Oxford, UK ${ }^{2}$ Oxford Centre for Genomic Medicine, Oxford University Hospitals NHS Foundation Trust, Oxford, UK

${ }^{3}$ Department of ENT, Oxford University Hospitals NHS Trust, Oxford, UK

Correspondence to

Mr Samuel Mackeith;

samuel.mackeith@ouh.nhs.uk

\section{INTRODUCTION}

Sudden sensorineural hearing loss (SSNHL) is a distressing condition that may lead to permanent disability with severe/profound deafness and tinnitus. While the aetiology varies, and is often idiopathic, urgent audiological assessment and management improves likelihood of hearing recovery. ${ }^{1}$ Bilateral vestibular schwannomas (VS) are a hallmark feature of neurofibromatosis type 2 (NF2) occurring in over $95 \%$ of patients. ${ }^{2}$ Up to $12 \%$ of patients with VS may present with SSNHL. ${ }^{3}$ Sudden hearing loss should be urgently assessed to determine if conductive or sensorineural using physical examination, otoscopy, tuning fork tests or audiometry. If found to be sensorineural, urgent treatment with high-dose oral and/or intratympanic steroids are indicated.

It is recognised that presentation of SSNHL to an ENT specialist is often delayed, with resulting delay in treatment which may lead to reduced chance of recovery. ${ }^{4}$ The reasons for this delay in presentation are likely to be multifactorial and may include a lack of awareness among patients and clinicians for the potential of sudden hearing loss to be sensorineural and a medical emergency. This most likely occurs due to the understandable initial assumption that new-onset hearing loss is most commonly due to a conductive cause such as wax impaction or glue ear following an upper respiratory illness. However, patients with NF2 are at significant increased risk of SSNHL due to their VS and the assumption that sudden hearing loss is most likely to be conductive is not appropriate and may lead to suboptimal management and outcomes for this otological emergency.

Alert Cards have been shown to improve patient and clinician response in other medical emergencies. ${ }^{5-7}$ We hypothesised therefore that use of a patient Alert Card would increase patient and clinician understanding of the need for urgent audiological assessment of sudden hearing loss in our at-risk population with the potential to reduce morbidity.

We aimed to determine if the introduction of a patient Alert Card would improve patient awareness of the need for urgent assessment of sudden hearing loss.

\section{MATERIALS AND METHODS}

Adults attending for routine review in the Southwest NF2 clinics were included. Children, new referrals, patients with pre-existing profound deafness or auditory implants were excluded.

We created a guideline for the management of SSNHL in patients with NF2 in line with published guidance. ${ }^{8}$ We designed a pocketsized Alert Card (figure 1) for patients and clinician use. This was given to all patients attending clinic with a verbal explanation of the guideline.

Questionnaires were administered by specialist nurses, prior to receipt of the Alert Card. The questionnaire asked how a patient would respond to suffering sudden hearing loss over a weekend. Four answers were available, with a single answer indicating urgent assessment being considered the most appropriate choice ('correct answer').

The questionnaires and intervention were performed between September 2016 and July 2018. The questionnaire was re-administered to returning patients between December 2016 and November 2019. The questionnaire allowed patients to provide free-text comments relating to their answer.

Patients who presented with SSNHL out-ofhours during the study period were recorded as post-intervention patients and their actions marked according to the response they most closely resembled.

Correct answer frequency difference, between encounters, was analysed for significance by McNemar test. The project was approved by local governance for patient data collection. 


\section{Oxford University Hospitals W/HS \\ NHS Foundation Trust}

NF2

Oxford Office:

- Nurse Line Oxford: Offices

Level 3

- Nurse Line Southampton:

West Wing

John Radcliffe Hospital Headington

Oxford

Email:

Website: www.ouh.nhs.uk/nf2

OX3 9DU

\section{If you notice a significant hearing loss:}

Contact the NF2 team Monday - Friday

If out of hours visit your GP or A\&E on the same day and take a copy of your latest audiogram.

Ask them to visit the OUH NF2 website and follow the guideline on sudden onset hearing loss.

We advise: clinical assessment to differentiate between a conductive loss and a sensorineural loss. If sensorineural loss, steroids may be recommended.

Figure 1

\section{RESULTS}

We received responses from 39 patients prior to intervention. Four patients were lost to follow-up: two receiving auditory implants, one relocating and one patient deceased. Before intervention, 15\% (6/39) of respondents identified the need for urgent assessment whereas $85 \%$ (33/39) did not (figure 2). Following provision of an Alert Card and guideline explanation, the number of patients correctly identifying the need for urgent assessment improved to $47 \%(17 / 36(p=0.0055))$. Those patients who attended a second post-intervention review chose correctly in $100 \%$ $(7 / 7)$ cases.

The most common non-urgent response selected, 'contacting the specialist office and awaiting advice', decreased from $58 \%(23 / 39)$ to $27 \%(10 / 36)$

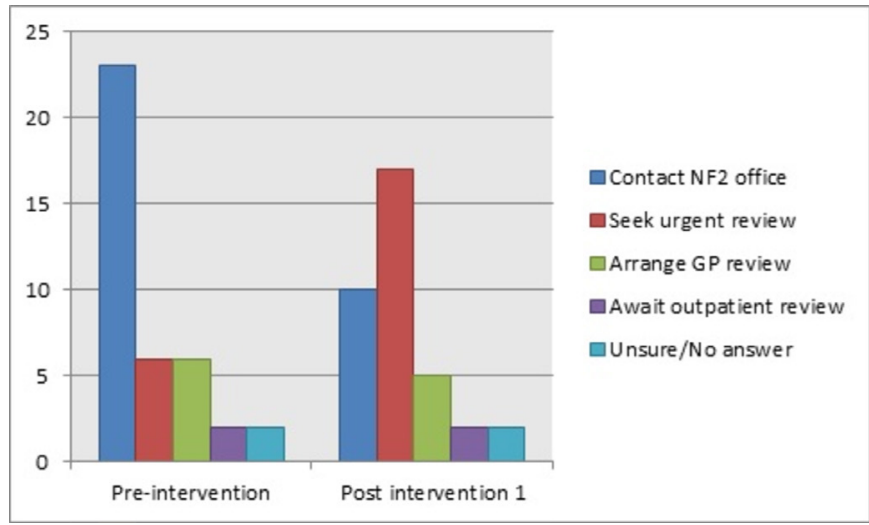

Figure 2 Change in response following intervention. post-intervention (figure 2). Two patients experienced SSNHL during the study after August 2018 and were added to the post-intervention results.

\section{DISCUSSION}

This study demonstrates initial low levels of patient awareness of the need for urgent assessment of SSNHL in the at-risk NF2 population. Alert Cards significantly improved expected patient response to sudden hearing loss. Of those patients who chose non-urgent assessment despite provision of an Alert Card, some offered free-text comments:

'Wouldn't think others would know about NF2, difficult explaining it all.'

'... A\&E wait, no knowledge of NF2 so no point.'

' $I$ know the answer is to go to A\&E but if I'm honest, I doubt if do it as it seems a bit dramatic. Wouldn't they just suggest I go to the doctor's?'

The selected free-text comments show patient reluctance to attend urgent services despite provision of alert card advice. This is an area that may benefit from qualitative research exploring the reasons for these comments and beliefs.

Our study was limited by several factors: the questionnaire surveyed an expected response and in most cases did not record an actual response to sudden hearing loss. Furthermore, the study did not directly measure clinician response nor compare outcomes.

\section{CONCLUSION}

Patient awareness of the need for urgent response to SSNHL is improved by the Alert Card and patient education. Since completion of this study, and discussion at our national NF2 symposium, NHSE recommendations include the use of Alert Cards across highly specialised services. ${ }^{9}$

This study supports the adoption of Alert Cards for SSNHL across all patients with NF2, and potentially sporadic vestibular schwannomas. This intervention is a low-cost, effective measure that has the potential for significant reduction in disability.

Acknowledgements Wendy Howard and Carolyn Redman assisted with data collection and problem shooting.

Collaborators Beatrice Emmanouil; Wendy Howard; Carolyn Redman.

Contributors JJB assisted with collection of the second arm of data collection. He wrote the substantive drafts of the body of text and background referencing. AM conceived the idea, laid out the methodology, created the intervention and collected the first arm of data. She laid out the framework for the study and contributed to revisions. RC contributed to the design of methodology and questionnaire, she collected data, reviewed the paper and organised the data. BE contributed to the design of methodology and questionnaire. She collated, organised and analysed the data. She created graphical figures and revised the manuscript through drafting. DH contributed significantly to the revisions of the paper through five drafts and the creation of the intervention. AP contributed significantly to the revisions of the paper through five drafts and the creation of the intervention. SM contributed significantly to the implementation and genesis of the project, the revisions of the paper through five drafts, and the implementation of the intervention and creation of guideline, and is the supervising consultant for the project. 
Funding The authors have not declared a specific grant for this research from any funding agency in the public, commercial or not-for-profit sectors.

Competing interests None declared.

Patient and public involvement Patients and/or the public were not involved in the design, or conduct, or reporting, or dissemination plans of this research.

Patient consent for publication Not required.

Provenance and peer review Not commissioned; externally peer reviewed.

Open access This is an open access article distributed in accordance with the Creative Commons Attribution Non Commercial (CC BY-NC 4.0) license, which permits others to distribute, remix, adapt, build upon this work non-commercially, and license their derivative works on different terms, provided the original work is properly cited, appropriate credit is given, any changes made indicated, and the use is non-commercial. See: http://creativecommons.org/licenses/by-nc/4.0/.

\section{REFERENCES}

1 Kuhn M, Heman-Ackah SE, Shaikh JA, et al. Sudden sensorineural hearing loss: a review of diagnosis, treatment, and prognosis. Trends Amplif 2011;15:91-105.
2 Emmanouil B, Houston R, May A, et al. Progression of hearing loss in neurofibromatosis type 2 according to genetic severity. Laryngoscope 2019;129:974-80.

3 Moffat DA, Baguley DM, von Blumenthal $\mathrm{H}$, et al. Sudden deafness in vestibular schwannoma. J Laryngol Otol 1994;108:116-9.

4 Anyah A, Mistry D, Kevern E, et al. Idiopathic sudden sensorineural hearing loss: average time elapsed before presentation to the otolaryngologist and effectiveness of oral and/or intratympanic steroids in late presentations. Cureus 2017;9:e1945.

5 Moghul M, Almpanis S. Stent cards: a simple solution for forgotten stents? BMJ Open Qual 2019;8:e000612.

6 Gooptu B, Ward L, Ansari SO, et al. Oxygen alert cards and controlled oxygen: preventing emergency admissions at risk of hypercapnic acidosis receiving high inspired oxygen concentrations in ambulances and A\&E departments. Emerg Med J 2006;23:636-8.

7 McBride A, Burey L, Megahed M, et al. The role of patient-held alert cards in promoting continuity of care for heart failure patients. Eur $J$ Cardiovasc Nurs 2014;13:71-7.

8 Chandrasekhar SS, Tsai Do BS, Schwartz SR, et al. Clinical practice guideline: sudden hearing loss (update). Otolaryngol Head Neck Surg 2019:161:S1-45.

9 England.nhs.uk. NHS England, Implementation Plan for the UK Strategy for Rare Diseases [Internet], 2019. Available: https://www. england.nhs.uk/publication/implementation-plan-for-the-uk-strategyfor-rare-diseases/ [Accessed 5 Dec 2019]. 